\title{
Lipopolysaccharide Core Defects in Salmonella typhimurium Mutants Which Are Resistant to Felix O Phage but Retain Smooth Character
}

\author{
By HELEN P. HUDSON, * A. A. LINDBERG† AND B. A. D. STOCKER \\ Department of Medical Microbiology, Stanford University School of Medicine, \\ Stanford, California 94305, U.S.A.
}

(Received 21 March 1978)

\begin{abstract}
FOR mutants of Salmonella typhimurium are resistant to Felix $\mathrm{O}$ phage, whose receptor includes the $N$-acetylglucosamine branch of the lipopolysaccharide (LPS) core, but smooth in cultural properties, antigenic character and phage sensitivity pattern (MacPhee et al., 1975). The $r f a($ FOR) genes determining the FOR character of nine mutants were transduced into a smooth cysE pyrE recipient: the nine FOR transductants (and a tenth FOR mutant) were then made $r f b$ (i.e. unable to make O chains) by transduction or Hfr crosses. The $r f b$ FOR strains were sensitive to FO phage but nearly all of them showed a somewhat reduced efficiency of plating and diminished rate of adsorption of the phage. This observation and the Ra (complete core) serological activity of their LPS (tested by haemagglutination inhibition) indicate the presence of some, but less than the normal number of, completed core chains in FOR $r f b$ LPS. On the basis of the sensitivities of the FOR transductants and their $r f b$ derivatives to various 'rough-specific' phages, their increased sensitivities to some antibiotics and to deoxycholate and the serological activity of the $r f b$ FOR LPS in various incomplete core systems, the mutants were divided into three groups: (i) five mutants with probable defects in previously undetected $r f a$ gene(s) concerned with formation of both the galactose I and the galactose II units of the LPS core; (ii) two mutants with defects inferred to affect the structure of the inner part of the core and also interfere with addition of the $\mathrm{N}$-acetylglucosamine branch; (iii) three mutants in which no type of incomplete core could be detected, probably affected in formation of the inner part of the core chain. The mutation of one mutant of the last class, unlike those of the other nine mutants tested, lay outside the $c y s E-p y r E$ segment, in the 90 to 116 min region of the linkage map.
\end{abstract}

\section{INTRODUCTION}

Felix O phage (FO phage) attacks nearly all Salmonella with a complete lipopolysaccharide (LPS) core; it acts both on smooth strains, whose LPS core bears O chains, and on rough strains which make complete core LPS without $O$ chains, i.e. classes $r f b$ and $r f a L$. FO phage does not attack rough mutants of other $r f a$ classes, which make incomplete LPS core (Wilkinson et al., 1972), nor does it act on galE or galU mutants, which make incomplete core because of their inability to synthesize UDPgalactose or UDPglucose. From its host-range and other evidence it was inferred (for review, see Lindberg, 1973) that the $\mathrm{N}$-acetylglucosamine side branch attached to the distal, glucose II, unit of the oligosaccharide chain of complete LPS core (Fig. 1) is an essential part of the site of adsorption of FO phage. MacPhee et al. (1975) described a class of Salmonella typhimurium mutants, called FOR, which are resistant to FO phage but smooth in cultural and serological

* Present address: Commonwealth Scientific and Industrial Research Organization, Division of Food Research, North Ryde, N.S.W., Australia.

$\dagger$ Present address: The National Bacteriological Laboratory, Stockholm, Sweden. 


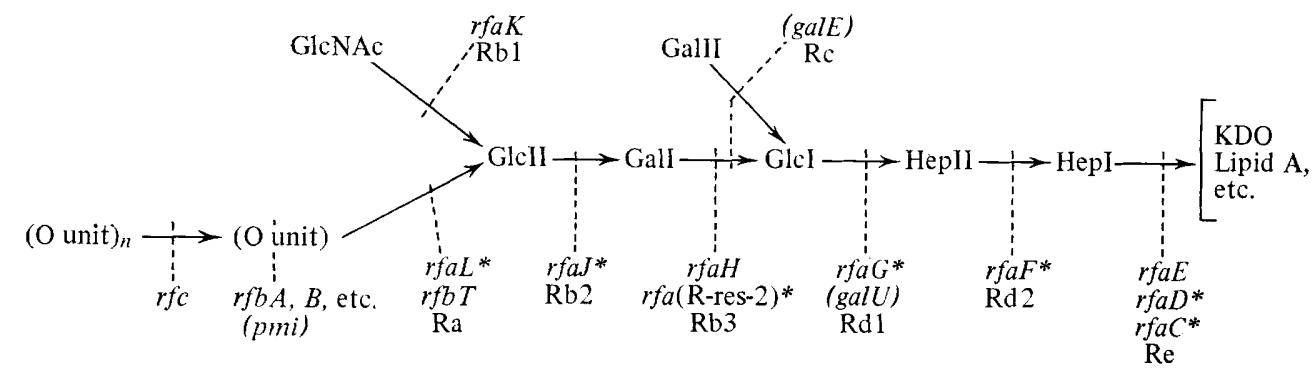

Fig. 1. Main features of Salmonella lipopolysaccharide structure, and genes concerned with formation of different units. Genes marked by an asterisk are located between cysE and pyrE. Genes galE and galU are indicated in parentheses because they have functions other than LPS synthesis. There is evidence (A. A. Lindberg \& C. G. Hellerqvist, unpublished data) that gene $r f a H$ is involved in formation of LPS units other than galactose I. Entries in Roman type (Ra, Rb1 etc.) are symbols for the 'chemotype' of LPS produced by mutants of the indicated class, i.e. for LPS completed up to the indicated block.

character and in their pattern of sensitivity to other phages. The FOR mutations of four such mutants were found to lie in the short cysE-pyrE segment of the linkage map, where most of the known $r f a$ loci are located. All the FOR mutants tested showed increased sensitivities to several antibiotics; in this respect they resembled $r f a$ mutants with defects in the deeper part of the LPS core (Roantree et al., 1977). FOR mutants were thought to have defects, of unknown nature, in their core structure reducing the number, and/or the accessibility to FO phage, of completed core oligosaccharide chains. Lindberg \& Svensson (1975) examined two of these FOR mutants in respect of ability to adsorb various phages and of LPS structure. Both FOR mutants contained as much LPS, with as high a proportion of O-specific sugars in it, as did their wild-type FO-sensitive parent strain; moreover, the average number of repeat units per $O$ chain was the same, about 30 , in the FOR mutants and the FO-sensitive parent. LPS extracted from two FOR mutants by the phenol/water method did not show any serological cross-reactivity with rough LPS of various types. These results were considered compatible with the hypothesis that FOR mutants have unidentified core defects. (If in the wild-type LPS all core units are completed but only some, say half, of them receive $O$ chains, then a mutation which prevented completion of some core units but did not alter the number or length of $O$ chains synthesized and attached to complete core units would result in a reduction in the number of core units without $O$ chains, i.e. in the number of FO receptor sites, without alteration in the total amount of O-specific material or in average $O$ chain length; failure to detect serological relatedness of FOR LPS to the incomplete core LPS tested might have resulted only from non-availability of an incomplete core LPS/antiserum system of the appropriate chemical character.)

It appeared from these two investigations that the FOR phenotype reflected alteration in the structure of the LPS core, without alteration in the number or length of $O$ chains attached to core. If so, it would be expected that FOR mutants would differ phenotypically from wild-type strains even if the production of $O$ chains was prevented, for instance by $r f b$ mutation. It would also be expected that resemblances between FOR core LPS and $r f a$ core LPS with similar structural defects would be more easily detected by serological methods if the FOR LPS, like the $r f a$ LPS, lacked O chains. The present investigation permitted such comparisons. We transferred genes determining the FOR character of nine mutants (eight previously investigated, one newly isolated) by transduction to an LT2 cysE pyrE his strain, then obtained $h i s^{+} r f b$ derivatives from each (and from a tenth FOR strain, mutated elsewhere than the $c y s E$-pyrE segment) by transduction or conjugational crosses. The effect of the FOR mutation on sensitivity to various phages and to antibiotics was then determined in the original mutants, in the set of nearly isogenic FOR transductants and in their $r f b$ derivatives. LPS was extracted from the $r f b$ FOR strains; unlike the LPS extracted 
Table 1. Main Salmonella typhimurium strains used

\begin{tabular}{|c|c|}
\hline Strain & Genotype \\
\hline $\operatorname{ser} A / 3$ & LT2 $\operatorname{ser} A 13$ \\
\hline SA968* & $\begin{array}{l}\text { LT2 HfrK22 leu ara } \mathrm{Thr}^{+} \\
\text {rfb-3061 }\end{array}$ \\
\hline SL 1027 & $\begin{array}{l}\text { LT2 met } A \operatorname{trp} B H l-b \\
H 2-e, n, x \text { 'cured of Fels } 2 \text { ' } \\
\text { flaA str } A \text { xyl met } E\end{array}$ \\
\hline SL 1034 & $\begin{array}{l}\text { LT2 met } A \text { trp } B H 1-b \\
H 2-e, n, x \text { 'cured of Fels } 2 \text { ' } \\
\text { faA } \operatorname{str} A \text { rf } f-465\end{array}$ \\
\hline SL1657 & $\begin{array}{l}\text { As sL } 1027 \text { but } h s p L T h s p S \\
\text { ilv galE496 }\end{array}$ \\
\hline SL3028 & LT2 pyrE125 cysE1710 \\
\hline SL $4522 \S$ & $\begin{array}{l}\text { M7471 } \div \text { (ColE } 1-30 \text { ) leu-105I } \\
\text { malB } 479 \text { cysII173 hisC527 } \\
\text { (amber) }\end{array}$ \\
\hline SL4469 & $\begin{array}{l}\text { LT2 pyrEI25 cysE } 1710 \\
\text { his-7067 }\end{array}$ \\
\hline SL4493 & As sL4469 but (P22.sie) \\
\hline SL5014 & $\begin{array}{l}\text { LT2 pyrE125 cysE } 1710 \\
\text { his-7068 (P22.sie) }\end{array}$ \\
\hline TV119 & $\begin{array}{l}\text { LT2 met } A \operatorname{trp} B H I-b \\
H 2 e, n, x \text { 'cured of Fels } 2 \text { ' } \\
\text { fla } A \text { str } A \text { rf } b-430\end{array}$ \\
\hline TV226 & $\begin{array}{l}\text { LT2 met } A \text { trpB 'cured of } \\
\text { Fels 2' (ColE1-30) his } \\
\text { rfaL } 447\end{array}$ \\
\hline TV $253 \S$ & $\begin{array}{l}\text { м7471 } \$ \text { (ColE1-30) leu-1051 } \\
\text { malB } 479 \text { hisC1150 } \\
\text { cysG1175 }\end{array}$ \\
\hline
\end{tabular}

Description or origin

FO-sensitive parent of FOR mutant SA28

Hfr parent used to introduce $r f b-3061$ his $^{+}$

FO-sensitive indicator strain

$r f c$ FO-sensitive indicator strain

FO-sensitive $\uparrow$ parent of FOR mutants SL4442 and SL4443

From K. E. Sanderson

FO-sensitive parent of FOR mutants SL4804 to SL4808

EMS-induced his mutant of $\mathrm{SL} 3028$

SL4469 made lysogenic

Lysogenic derivative of EMS-induced his mutant of SL 3028

Used as transductional donor of $h i s^{+} r f b-430$

Transductional donor of cys $E^{+} r f a L 447$ or of pyrE ${ }^{+}$rfaL 447

FO-sensitive parent of FOR mutants SL4504 SL4505§
References

Sanderson \& Saeed (1972)

Sanderson et al. (1972)

Wilkinson et al. (1972), Kuo \& Stocker (1972)

Wilkinson et al. (1972)

Ornellas \& Stocker (1974)

MacPhee \& Stocker (1969), MacPhee et al. (1975)

Subbaiah \& Stocker (1964)

Subbaiah \& Stocker (1964); Kuo \& Stocker (1972)

Krishnapillai et al. (1971); MacPhee et al. (1975)

* Strain SA968, HfrK22 is described (Sanderson et al., 1972) as thr, but was found by us to be Thr ${ }^{+}$, and also rough, due to a his-linked mutation, assigned symbol $r f b-3061$.

$\dagger$ SL1657, because of its galE defect, is phenotypically smooth and sensitive to FO phage only if grown on galactose-supplemented medium.

$\$$ Salmonella typhimurium M7471 is of type (or subspecies) 'FIRN', i.e. non-fimbriate, inositol-negative and rhamnose-negative (Morgenroth \& Duguid, 1968).

$\S$ Note that in an earlier paper (MacPhee et al., 1975, Table 1) TV253 was by error shown as parent of FOR mutants SL 4804 to SL4808, instead of as parent of SL4504 and SL4505; and SL4522 was by error shown as parent of mutants SL4504 and SL4505, instead of as parent of mutants SL4804 to SL4808.

from two smooth FOR strains (Lindberg \& Svensson, 1975) most of these LPS showed serological relatedness to one or more types of core-defective LPS due to $r f a$ mutation. We also investigated the map position of genes causing the FOR mutation; nine of ten mutations tested were located in the main cluster of $r f a$ genes, between $c y s E$ and $p y r E$; the tenth mutation, causing the FOR phenotype of a newly isolated mutant, was located elsewhere.

\section{METHODS}

Media. The complete media used were Oxoid blood agar base (code CM55) and Oxoid nutrient broth (code CM67). Each of these contains sodium chloride $\left(5 \mathrm{~g} \mathrm{l}^{-1}\right)$ and allows efficient plating of $\mathrm{P} 1$ phage (Ornellas \& Stocker, 1974), which probably indicates the presence of sufficient divalent cations. These media were supplemented with glucose and galactose $\left(5 \mathrm{~g} \mathrm{l}^{-1}\right.$ of each) for tests on phage sensitivity of galE strains, and with cystine $\left(25 \mu \mathrm{g} \mathrm{ml}^{-1}\right)$ for tests on phage sensitivity of $c y s$ strains. The defined medium used was Davis minimal, with glycerol $\left(2 \mathrm{ml}^{-1}\right)$ as main carbon and energy source; citrate and glycerol were replaced by xylose $\left(5 \mathrm{~g} \mathrm{l}^{-1}\right)$ for selection of $x y l^{+}$recombinants. 
Bacterial strains and phages. The main strains used are listed in Table 1. The FOR strains used (see Table 2) comprised eight mutants described by MacPhee et al. (1975), seven of them in sublines of strain $M 7471$, and two mutants which we isolated in an LT2 derivative (see below). To facilitate the introduction of gene $r f b$ by transduction or conjugation, his mutants were secured by exposure to ethyl methanesulphonate in strains SL3028 (LT2 cysE pyrE) and SL4442 (an FOR mutant in an LT2 stock, Table 2).

The phages used to characterize mutants included phage FO and the smooth-specific and rough-specific phages defining various 'phage sensitivity patterns' (Wilkinson et al., 1972). We used, in addition: phage KB1, a general transducing phage active on strains lysogenic for P22 (Boro \& Brenchley, 1971), which appears to have the same adsorption requirements as P22 (Stocker, unpublished data); and a stock of phage $\phi \times 174$ (obtained from R. L. Sinsheimer, California Institute of Technology, U.S.A.), propagated on an E. coli strain, to avoid selection of host-range mutants, and found to attack only rough mutants of patterns $\mathbf{R}$ sensitive or D-1 (cf. Wilkinson et al., 1972). For transduction we used P22 variants, either P22. HT105/1, a 'high-transducing' mutant (Schmieger, 1972), or P22. L4, an int mutant (Smith \& Levine, 1967). Phage ES18 was used to transduce the linked $h i s^{+}$and $r f b$ genes of strain Tv119 (Subbaiah \& Stocker, 1964) into his recipients. Strains to be used as transductional recipients were usually first made lysogenic for P22. sie-6-1; this is a P22 mutant deficient in superinfection-exclusion (Walsh \& Meynell, 1967; Levine, 1972) which therefore as prophage confers immunity to P22 without reducing the efficiency of P22 transduction and (like P22 wild-type; Kuo \& Stocker, 1970) increases the frequency of transduction by phage ES18. Phage P22. vir-3 (obtained from C. van Beveren, Department of Molecular Biology, Tufts University School of Medicine, U.S.A.), a virulent mutant able to lyse strains lysogenic for P22.sie (Levine, 1972), was used to test the ability of strains lysogenic for that phage to adsorb P22. In one experiment we used phage P22.a1, a mutant deficient in 'converting' ability in respect of antigenic factor O1 (Young et al., 1964).

Phage and genetic methods. Phages were propagated on appropriate LT2 lines, 'cured' of Fels 2 (Wilkinson et al., 1972), by the soft agar layer method, and were titrated by the drop-on-lawn method (Gemski \& Stocker, 1967). Phage sensitivity was tested by application of drops of phage, usually at a concentration of $10^{8}$ plaque-forming units (p.f.u.) $\mathrm{ml}^{-1}$ to nutrient agar plates inoculated by flooding or streaking from broth cultures. Rates of irreversible adsorption of phage FO were measured by the chloroform method (Lindberg \& Svensson, 1975); the adsorbing suspension contained exponential-phase broth-grown bacteria, at about $2 \times 10^{8} \mathrm{ml}^{-1}$, in $0.05 \mathrm{M}$-Tris $/ \mathrm{HCl}$ buffer, $\mathrm{pH} 7 \cdot 2$, with $0 \cdot 15 \mathrm{M}-\mathrm{NaCl}$.

Transduction of nutritional characters was carried out by the drop-on-lawn method (MacPhee et al., 1975) on defined medium, or on nutrient agar, in the case of transduction of $c y s E^{+}$, since this medium (like most broth-based media) contains amounts of cystine which are growth-limiting for cysE mutants (Kuo \& Stocker, 1972). Conjugational crosses involving $\mathrm{Hfr}$ strains were made by standard methods.

LPS extraction and haemagglutination-inhibition test. Cultures were grown with shaking in a tryptone/ yeast extract/glucose medium (Lindberg \& Holme, 1972). LPS was extracted from dried cells by the phenol/ chloroform/petroleum ether method (Galanos et al., 1969). Passive haemagglutination-inhibition tests were performed using Takatsy micro-plates and suspensions $(1 \cdot 2 \%, \mathrm{v} / \mathrm{v})$ of washed human erythrocytes coated with appropriate lipopolysaccharides (Lindberg \& Hellerqvist, 1971). Antisera specific for different core types were raised in rabbits by immunization with heat-killed bacteria of appropriate rough strains: before use, sera were inactivated $\left(56^{\circ} \mathrm{C}, 30 \mathrm{~min}\right)$ and absorbed with washed human red cells. LPS to be tested as inhibitor was treated with $0.25 \mathrm{M}-\mathrm{NaOH}$ at $56^{\circ} \mathrm{C}$ for $60 \mathrm{~min}$; this removed ester-linked fatty acids and thereby increased solubility.

Antibiotic sensitivity tests. Minimum inhibitory concentrations were determined by the method of Roantree et al. (1977), in which an inoculum of about 200 bacteria from a diluted broth culture was deposited on the surface of agar plates by use of a multiprong replicator. The broth used for growing the cultures was brain heart infusion (Difco), supplemented with cystine for cysE strains. The agar medium used was Oxoid sensitivity test agar (code CM215).

\section{RESULTS}

\section{Phenotype of FOR mutants}

The FOR mutants tested (Table 2) comprised two newly isolated mutants and eight of those reported by MacPhee et al. (1975) (but we used strain SA486, the HfrK3 variant of the FOR $\mathrm{F}^{+}$strain SA28 used by them). The two new FOR mutants, sL4442 and SL4443, were obtained, by selection for resistance to $\mathrm{FO}$ phage at $42{ }^{\circ} \mathrm{C}$ on galactose-supplemented nutrient agar, from a mutagen-treated culture of strain SL 1657 , recorded as galE (i.e. deficient of UDPgalactose epimerase) and therefore resistant to FO phage except when grown with galactose. However, both mutants proved to be galactose-positive, presumably because they arose in a $\mathrm{Gal}^{+}$'revertant' clone present in, or perhaps constituting, the broth 
culture of SL 1657 used for isolation of mutants - the galactose character of this particular culture was not checked at the time of isolation of the mutants. (We think it likely that the galactose-positive character resulted from reversion at $\mathrm{gal}$, but suppressor mutation has not been excluded.) Both mutants were of the FOR phenotype at $37^{\circ} \mathrm{C}$ as well as at $42{ }^{\circ} \mathrm{C}$. All 10 mutants had the typical FOR phenotype in that they gave smooth-looking colonies on nutrient agar, uniform growth in broth and positive slide-agglutination tests with anti-O4 and anti-O5 sera. The FOR mutants were tested for 'heat stability' of cultures in beef extract broth (Schmidt et al., 1969): all cultures remained uniformly turbid after heating for $1 \mathrm{~h}$ at $100^{\circ} \mathrm{C}$, as expected for smooth strains. In phage pattern tests (Wilkinson et al., 1972) all the mutants gave the expected FOR pattern, being sensitive to all three smoothspecific phages, resistant to all the rough-specific phages used, and resistant to FO phage, which produced no plaques and no detectable thinning of growth even when applied at $10^{10}$ p.f.u. $\mathrm{ml}^{-1}$.

\section{Genetic analysis for FOR mutants}

MacPhee et al. (1975) showed that the genes causing the FOR phenotype of four mutants were cotransducible with $c y s E^{+}$and with $p y r E^{+}$at frequencies $>1 \%$, and inferred that the genes concerned were located between $c y s E$ and $p y r E$, a short segment of the chromosome which includes nearly all the $r f a$ genes so far identified. To test for such map position and to permit testing of FOR genes in a uniform background, we used transducing phage grown on each of the $10 \mathrm{FOR}$ mutants to evoke $c y s E^{+} p y r E^{+}$transductants from strain SL3028, a cys $E$ pyrE double mutant (received from K. Sanderson) or from its his mutant made lysogenic for P22. sie. Phage P22.HT105/1 grown on each of the 10 FOR mutants evoked $c y s^{+} p y r^{+}$ transductants, about 5 per $10^{9}$ p.f.u., from the cysE pyrE recipient. Purified transductants evoked by nine of the 10 lysates included some, usually a majority, which were entirely or substantially resistant to FO phage and inferred to be FOR transductants. One such transductant from each of the nine sets (and control, FO-sensitive transductants obtained by application of phage grown on three FO-sensitive parents of FOR mutants) were used for tests of the FOR phenotype in a uniform genetic background. A $r f b$ derivative was made from each of the set of FOR and control transductants, either by cotransduction of $r f b$ with his ${ }^{+}$from TV119 (Subbaiah \& Stocker, 1964) by phage ES18, or by a conjugational cross using an Hfr donor found to be $r f b$ (Table 1), with selection for the his ${ }^{+}$gene of the donor. The $r f b$ FOR derivatives thus obtained were used for tests of the effect of FOR mutation on phage sensitivity etc. of strains lacking $O$ chains. All of nine $c y s E$ pyrE transductants evoked by phage grown on FOR mutant SL 4442 were fully sensitive to FO phage. As the FOR gene of this mutant could not be transferred to the standard host, a his mutant was obtained from it by exposure to ethyl methanesulphonate: the his mutant, SL5024, and a $r f b$ derivative of it obtained by transduction were used for tests of the effect of this FOR mutation on phenotype in a $r f b^{+}$or $r f b$ strain.

The frequencies of cotransduction of FOR genes with $c y s^{+}$and with pyrE $E^{+}$were determined using the same phage lysates, adjusted to about $10^{8}$ p.f.u. $\mathrm{ml}^{-1}$, and with selection for only one donor nutritional character instead of two. The recipient strains used in different experiments differed only in that some were his $^{+}$and that not all had been made lysogenic for P22. sie. Some cys $E^{+}$FOR or pyrE $E^{+}$FOR transductants grow more slowly than $c y s E^{+}$ or pyr $E^{+}$transductants not acquiring the donor FOR gene (MacPhee et al., 1975). To avoid inadvertent selection of the faster growing class, all transductant colonies growing within a certain area on the selection plate were picked and purified. Sensitivity to FO phage and unselected nutritional character $\left(\mathrm{Cys}^{+}\right.$or $\left.\mathrm{Pyr}^{+}\right)$were tested after purification by singlecolony isolation on selective medium. The cotransduction frequencies shown in Table 5 are the means from two experiments in each of which about 50 transductants of each class were scored. Several FOR genes were cotransduced with $c y s E$ and with $p y r E$ at about equal frequencies, indicating a location about midway between these two loci: those of mutants SL4505 and SL4804 gave cotransduction frequencies suggesting a location closer to $c y s E$ 
than to pyrE, while the results with the mutation of SL4504, and perhaps those with two other mutants, suggested a location closer to pyrE than to cys $E$. (The frequency of cotransduction of cys $E^{+}$with $p y r E^{+}$, from all crosses summed, was $9 / 797=1 \cdot 1 \%$, and that of $p y r E^{+}$with $c y s E^{+}$was $4 / 842=0.48 \%$.)

Two anomalies encountered in these experiments did not prevent measurement of cotransduction frequencies. (i) In some preliminary experiments most apparent $c y_{s} E^{+}$transductant colonies, obtained by selection on defined medium with uracil and histidine, failed to grow when streaked for purification on the same medium. This perhaps resulted from heterogeneity of the recipient population, strain SL5014, in ability to grow on supplemented defined medium. We avoided the difficulty by using a single-colony re-isolate of strain SL5014 from supplemented defined medium, preserved at $-70{ }^{\circ} \mathrm{C}$ in broth with glycerol, as inoculum for growth of recipient cultures in subsequent transduction experiments. (ii) A few $(<5 \%) c y s E^{+}$or pyrE $E^{+}$transductant clones, examined by testing the phenotype of four single colonies from a purification plate, were found to be mixed in respect of one or both unselected characters, more than one stable recombinant type being found. At least one clone which segregated FO-sensitive and FOR types was itself scored, before singlecolony purification, as FO-sensitive - which we take as evidence that the wild-type allele is dominant to the mutant FOR gene concerned. (The cotransduction frequencies recorded in Table 5 were determined in experiments in which only a single re-isolate from each transductant clone was tested for unselected characters, so that the presence of a few 'mixed' clones would not have been detected.)

We attempted to map two $r f a(F O R)$ mutations, inferred to affect LPS core structure, in relation to gene $r f a L$, concerned with addition of $O$ chains to complete LPS core (Wilkinson et al., 1972) and inferred to lie about midway between cysE and pyrE (Kuo \& Stocker, 1972). Phage ES18 grown on TV226 ( $r f a L 447$ ) was used to evoke $c y s E^{+}$or $p y r E^{+}$transductants from cysE FOR or pyrE FOR recipients, themselves obtained by $\mathrm{P} 22$ transduction of the FOR genes of two mutants to a cysE pyrE recipient. All four combinations of wild-type and mutant $r f a L$ and $r f a(F O R)$ allele could be recognized by phage sensitivity patterns. In the cross involving gene $r f a-3058$, of FOR mutant SA486, all the four transductant clones recombinant in respect of $r f a L$ and $r f a(F O R)$ found amongst 41 clones tested could have arisen by two crossovers if the order is $c y s E-r f a L-r f a(\mathrm{FOR})-p y r E$ : so also could three of the four recombinant transductants, among 81 tested, in the cross involving mutation rfa-951 of FOR mutant SL4443.

As the mutation causing the FOR phenotype of mutant SL4442 was not in the cysE-pyrE segment, we crossed this mutant, as recipient, with various $\mathrm{Hfr}$ strains, all smooth and fully sensitive to FO phage, and scored FO-sensitivity as an unselected marker. All the results (Hudson, 1976) were compatible with location of $r f a(F O R)-950$ between the 'origin' of S. abony $\mathrm{HfrH} 12$ at about $90 \mathrm{~min}$ and $x y l$ at $116 \mathrm{~min}$.

\section{Phenotype of FOR (and control) transductants and their rfb derivatives}

The nine FOR cysE $E^{+}-p y r E^{+}$transductants (and the three 'control' transductants, each given the $c y s E^{+}-p y r E^{+}$region from one of the FO-sensitive parent strains) all gave smoothlooking colonies and turbid broth cultures. All were unaffected by phages P22.c2 and P22h.c2, because of their P22 lysogeny (for P22. sie, if derived from a cysE pyrE recipient made lysogenic for this phage, otherwise for the transducing phage, P22.HT105/1). Apart from this P22 immunity, the control transductants showed the phage sensitivities expected for smooth (wild-type) strains (Table 2). They were 'fully sensitive' to FO phage, allowing an efficiency of plating (e.o.p.) of about 1 ; in this they resembled other smooth derivatives of strain LT2 and differed from smooth sublines of strain M7471 (such as TV253 and SL4522, the parents of most of the FOR mutants), on which FO phage plates with an efficiency of only about $10^{-2}$ (MacPhee et al., 1975). The phage reactions of the FOR transductants, determined with phages at the routine concentration $\left(10^{8}\right.$ p.f.u. $\left.\mathrm{ml}^{-1}\right)$ conformed to pattern 
Table 2. Sensitivity* to FO phage and to rough-specific phages of: (i) transductants given cysE-rfa-pyrE segment from FOR mutants (or their FO-sensitive parents), and their rfb derivatives; (ii) rfa mutants of classes giving different phage sensitivity patterns

\section{(i) Transductants and their rfb derivatives}

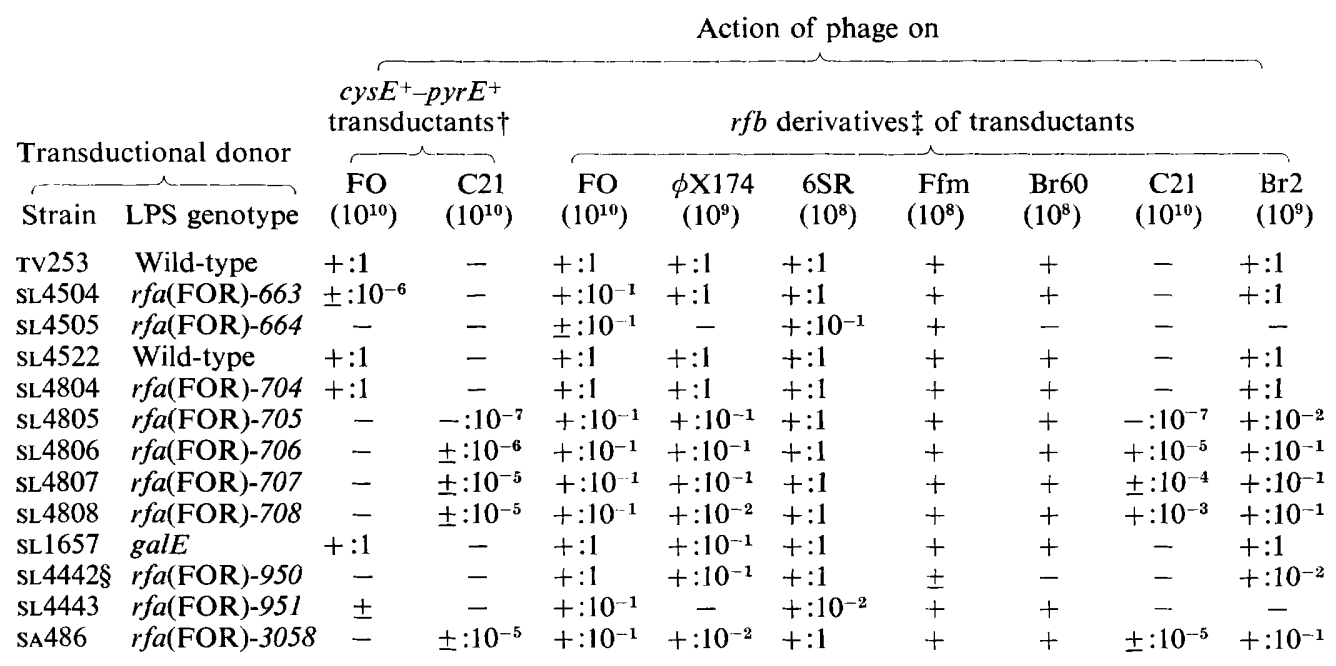

(ii) Rough, etc. mutants of various phage sensitivity patterns

Class

\begin{tabular}{|c|c|c|}
\hline Pattern & $\begin{array}{l}\text { Genetic } \\
\text { class(es) }\end{array}$ & $\begin{array}{c}\text { LPS } \\
\text { constitution } \mid\end{array}$ \\
\hline Smooth** & Wild-type & $\mathrm{Ra} \leftarrow(\mathrm{O})_{n}$ \\
\hline Zsr & $r f c$ & $\mathrm{Ra} \leftarrow(\mathrm{O})$ \\
\hline R-sens & $\begin{array}{l}r f b, r f a L \\
\text { and } p m i\end{array}$ & $\mathrm{Ra}$ \\
\hline D- $1 * *$ & $r f a K$ & $\mathbf{R b} 1 \leftarrow(\mathrm{O})_{n} \dagger \dagger$ \\
\hline R-res-1 & $r f a J$ & $\mathrm{Rb} 2$ \\
\hline R-res-2 & $r f a($ R-res-2) & $\mathrm{Rb} 3$ \\
\hline Epi-1 & galE, rfaH $\ddagger \ddagger$ & $\mathrm{Rc}$ \\
\hline Epi-2 & $\mathrm{gal} U, \mathrm{rfaG}$ & Rd1 \\
\hline Hep-2 & $r f a F$ & $\mathbf{R d} 2$ \\
\hline Hep-1 & $\begin{array}{r}r f a E, r f a D \\
\text { and } r f a C\end{array}$ & $\mathbf{R e}$ \\
\hline
\end{tabular}

Action of phages

$\begin{array}{ccccccc}\text { FO } & \phi \times 174 & 6 \mathrm{SR} & \text { Ffm } & \text { Br60 } & \text { C21 } & \text { Br2 } \\ \left(10^{8}\right) & \left(10^{8}\right) & \left(10^{8}\right) & \left(10^{8}\right) & \left(10^{8}\right) & \left(10^{8}\right) & \left(10^{8}\right)\end{array}$

$\begin{array}{lllllll}+ & - & - & - & - & - & - \\ + & - & - & - & - & - & - \\ + & + & + & + & + & - & +\end{array}$

$\begin{array}{cccc}- & + & + & + \\ - & + & - & + \\ - & - & - & + \\ - & - & - & + \\ - & - & - & + \\ - & - & - & + \\ - & - & - & +\end{array}$

* Phages were applied at the indicated concentration $\left(10^{10}, 10^{9}\right.$ or $10^{8}$ p.f.u. $\left.\mathrm{ml}^{-1}\right)$. + , Confluent lysis; \pm , plaques or 'thinning' of growth; -, no visible effect. Figure after the colon is the efficiency of plating.

$\dagger$ All the $\left(r f b^{+}\right)$FOR transductants were sensitive to the smooth-specific phages 9NA and KB1 (and to P22.vir, if derived from recipients lysogenic for P22.sie) and resistant to all the rough-specific phages used, except for the indicated sensitivity of five of them to C21.

$\$$ All $r f b$ derivatives were resistant to smooth-specific phages (and to rough-specific phage P221.c2 because of their P22 lysogeny).

$\S$ The FOR mutation of SL4442 is not in the cysE-pyrE segment. The phage sensitivities shown are those of a his mutant of sL4442, and of its $r f b$ derivative.

il See Fig. 1 for structure of LPS cores indicated as Ra, Rbl etc. $(\mathrm{O})_{n}$ indicates a chain of $\mathrm{O}$ units; (O) indicates a single $\mathrm{O}$ unit.

Ifditional classes, of patterns called D-2 and D-3, have patterns like R-res-1 and R-res- 2 with addition of sensitivity to smooth-specific phages.

** Smooth pattern includes sensitivity to smooth-specific phages (unless immune by lysogeny); pattern D-1 includes partial sensitivity to smooth-specific phages (Wilkinson et al., 1972; Gemski \& Stocker, 1967).

$\dagger \dagger$ The LPS of $r f a K$ mutants, of pattern D-1, contains only a small amount of $\mathrm{O}$ chains.

$\ddagger \ddagger$ The LPS of $r f a H$ mutants is heterogeneous, with chains ending at various points; chains of type Rc presumably account for the C21-sensitivity of $\mathrm{raH}$ mutants (Lindberg \& Hellerqvist, unpublished data). 
FOR, except that two of the nine were 'thinned' by FO phage at $10^{8}$ p.f.u. $\mathrm{ml}^{-1}$, one allowing an e.o.p. of about 1. Tests with concentrated phage showed that one other transductant was slightly sensitive to FO phage (e.o.p. $<10^{-8}$ to $10^{-7}$ ) and that phage $\mathrm{C} 21$ plated with low efficiency $\left(10^{-7}\right.$ to $\left.10^{-5}\right)$ on five of them (Table 2).

The $r f b$ derivatives, transductant or transconjugant, isolated from the nine FOR transductants (and from the his subline of FOR mutant SL4442, whose FOR mutation is outside the main $r f a$ cluster) were easily recognized by their rough-looking colonies. The phage sensitivity pattern of one $r f b$ clone in each of the 10 sets was determined (Table 2); $r f b$ derivatives of the three 'control' transductants were also tested. All were, as expected, resistant to all the smooth-specific phages, and resistant (immune) also to the rough-specific phage P221 .c2, which does not attack (rough) strains lysogenic for P22 (Wilkinson et al., 1972). The $r f b$ derivatives of the control strains gave the pattern (R-sensitive) expected for strains with complete core LPS lacking $O$ chains (Table 2). The $10 \mathrm{rfb}$ derivatives of FOR transductants (or of the his mutant of FOR strain SL4442) gave sensitivity patterns which approximated to R-sensitive. However, though all of them showed confluent lysis when spotted with $\mathrm{FO}$ phage at $10^{8}$ p.f.u. $\mathrm{ml}^{-1}$, only two allowed this phage to plate with an efficiency about 1 ; on the other eight, it plated with an efficiency sometimes about $0 \cdot 1$, but variable; sometimes no distinct plaques were seen at any concentration, so that an e.o.p. could not be calculated. The $r f b$ derivatives of the five FOR transductants that were slightly sensitive to phage $\mathrm{C} 21$ likewise supported production of plaques by this phage, but with an e.o.p. of only $10^{-7}$ to $10^{-3}$. (Phage $\mathrm{C} 21$ isolated from a plaque produced on one such $r f b$ FOR strain was indistinguishable from the original phage C21 in its host-range; thus the rare plaques observed are not produced by host-range mutants of the phage.) The five C21-sensitive $r f b$ FOR strains were sensitive to all the other rough-specific phages used (except P221.c2); but all of them allowed an e.o.p. of only $10^{-2}$ or $10^{-1}$ by phages $\mathrm{Br} 2$ and $\phi \mathrm{X} 174$ (Table 2). The other five $r f b$ FOR strains were unaffected by $\mathrm{C} 21$, even at $10^{10}$ p.f.u. $\mathrm{ml}^{-1}$, and the phage pattern of three of these five differed from the R-sensitive pattern in that they were resistant to one or more of the rough-specific phages $\phi \times 174, \mathrm{Br} 2$ and $\mathrm{Br} 60$.

In summary, the LT2 cys $E^{+}-p y r E^{+}$transductants with the $r f a(\mathrm{FOR})$ alleles of different FOR mutants approximated in phage sensitivity to pattern FOR, but three of the nine were incompletely resistant to FO and five were slightly sensitive to phage $\mathrm{C} 21$ (e.o.p. $10^{-5}$ to $10^{-7}$ ); their $r f b$ derivatives were all sensitive to FO; five of the $r f b$ FOR strains showed the same partial sensitivity to $\mathrm{C} 21$ as their $r f b^{+}$FOR parents; and several of the $r f b$ FOR strains were resistant or partly resistant to one or more of the rough-specific phages $\phi \mathrm{X} 174, \mathrm{Br} 2$ and $\operatorname{Br} 60$.

\section{Rates of attachment of FO phage to rfb FOR strains}

We measured the rate of irreversible attachment (expressed as adsorption rate constant, A.R.C.) of FO phage to the $r f b$ derivatives of the transductants (Table 5). The rates for the three control strains, each with the $c y s E^{+}-p y r E^{+}$segment from an $\mathrm{FO}$-sensitive parent strain, varied from $154 \times 10^{-11}$ to $286 \times 10^{-11} \mathrm{~min}^{-1}$. The rate for the $r f b$ derivative with the FOR gene of mutant SL4804 did not differ significantly from that for the relevant control strain, and that for the $r f b$ derivative with the FOR gene from mutant SL4504 was about half that for its control strain. The rates for the other eight test strains ranged from one-tenth to one-fifth of the rates for their control strains, as expected if FOR mutants make LPS with less than the normal number of completed core chains.

\section{Antigenic character of FOR rfb lipopolysaccharide}

Lipopolysaccharides (LPS) from the $r f b$ derivatives of the FOR and control transductants were characterized by inhibition of haemagglutination (Table 3). The LPS/antibacterialserum systems used comprised complete core and seven different incomplete core forms (Fig. 1, Table 3). None of the eight rough LPS inhibited any heterologous system even at 
Table 3. Haemagglutination inhibition* by LPS from rfb derivatives of $\mathrm{cys}^{+}$pyr $^{+}$ transductants with rfa region from FOR mutants or FO-sensitive parents

Haemagglutination (LPS/antibacterial serum) system: chemotype, strain no. and mutation

\begin{tabular}{|c|c|c|c|c|c|c|c|c|c|}
\hline \multirow{2}{*}{\multicolumn{2}{|c|}{$\begin{array}{l}\text { Source of cys } E-p y r E \\
\text { segment in transductant }\end{array}$}} & \multicolumn{8}{|c|}{-1} \\
\hline & & \multirow{2}{*}{$\begin{array}{l}\mathrm{Ra} \\
\mathrm{sH} 180 \\
r f b\end{array}$} & \multirow{2}{*}{$\begin{array}{r}\mathrm{Rb} 1 \\
\mathrm{SL} 733 \\
\mathrm{rfaK}\end{array}$} & \multirow{2}{*}{$\begin{array}{c}\mathrm{Rb} 2 \\
\mathrm{~T} \vee 160 \\
r f a J\end{array}$} & \multirow{2}{*}{$\begin{array}{c}\text { Rb3 } \\
\text { TV148 } \\
r f a(\mathrm{R}-\mathrm{res}-2)\end{array}$} & \multirow{2}{*}{$\begin{array}{l}\text { Rc } \\
\text { SL805 } \\
\text { galE }\end{array}$} & \multirow{2}{*}{$\begin{array}{l}\text { Rd1 } \\
\text { SL1032 } \\
r f a G\end{array}$} & \multirow{2}{*}{$\begin{array}{l}\mathrm{Rd} 2 \\
\mathrm{SL} 1181 \\
r f a F\end{array}$} & \multirow{2}{*}{$\begin{array}{c}\mathrm{Re} \\
\mathrm{SL} 1102 \\
r f a E\end{array}$} \\
\hline Strain & FO character & & & & & & & & \\
\hline TV253 & FO-sens & 1 & - & - & - & - & - & - & - \\
\hline SL4504 & FOR & 1 & - & - & - & - & - & - & - \\
\hline SL 4505 & FOR & 2 & 4 & - & - & - & - & - & 125 \\
\hline SL4522 & FO-sens & 1 & 62 & - & - & - & - & - & - \\
\hline SL4804 & FOR & 4 & - & - & 125 & - & - & - & - \\
\hline SL4805 & FOR & 1 & - & - & - & 2 & - & - & - \\
\hline SL4806 & FOR & 4 & 125 & - & - & 32 & - & - & - \\
\hline SL4807 & FOR & 1 & - & - & - & 16 & - & - & - \\
\hline SL4808 & FOR & 4 & - & - & - & 4 & - & - & - \\
\hline SL4442† & FOR & 2 & 62 & - & - & - & - & - & - \\
\hline SL 4443 & FOR & 8 & 4 & - & - & - & - & - & - \\
\hline SA486 & FOR & 1 & - & 62 & - & 16 & - & - & - \\
\hline \multicolumn{2}{|c|}{$\begin{array}{l}\text { Minimum inhibitory } \\
\text { amount of homo- } \\
\text { logous LPS }\end{array}$} & 1 & 2 & 1 & 4 & 2 & 4 & 8 & 32 \\
\hline
\end{tabular}

* Each entry is the minimum amount ( $\mu \mathrm{g}$ per well) of indicated LPS needed to inhibit naked-eye haemagglutination in the indicated system (human red cells coated with LPS plus homologous antibacterial serum). The results show the amount of LPS needed to inhibit about two haemagglutinating units of serum; tests with four units gave qualitatively identical results. - , No inhibition at $125 \mu \mathrm{g}$ per well.

$\dagger$ LPS was extracted from a $r f b$ derivative of a his mutant of FOR mutant SL4442, whose mutation is not cotransducible with cysE or pyrE.

$125 \mu \mathrm{g}$ per well, the highest amount tested. Two serum concentrations, in the range 1 to 8 haemagglutinating units, were used; the sensitivity of the systems to inhibition was checked by determination of the minimum amount of homologous LPS needed to inhibit each system, at each of the two serum concentrations used. Table 3 records the results with the test LPS at the lower serum concentration. As expected, all the LPS were active in the Ra (complete core) system, the minimum amounts needed for inhibition ranging from 1 to $8 \mu \mathrm{g}$. LPS from the two control strains were inactive in all the incomplete core systems except for inhibition of the $\mathrm{Rb} 1$ system by one of them at $62.5 \mu \mathrm{g}$, a reaction of doubtful significance in view of the inhibition of this system by homologous LPS at only $2 \mu \mathrm{g}$ per well. The LPS from all the five strains sensitive to phage C21 had significant activity in the Rc system, which suggests that their sensitivity to that phage may result from the presence of some core chains lacking both galactose units, as are found in the Rc LPS of galE mutants. The LPS from two of these five strains were also weakly active in one other system, $\mathrm{Rb} 1$ or Rb2. The LPS from three strains, with $r f a(\mathrm{FOR})$ genes from SL4504, SL4804 and SL4442, were inactive in all incomplete core systems, or showed only weak, doubtfully significant, activity in the Rb1 or Rb3 system. LPS from those strains with $r f a(F O R)$ genes from mutants SL4505 and SL4443 were strong inhibitors of the Rb1 system; the former at $125 \mu \mathrm{g}$ per well also inhibited the Re system, an activity which though weak may be significant since $32 \mu \mathrm{g}$ of homologous LPS were needed to inhibit at the same serum concentration.

\section{Effect of FOR mutation on sensitivity to antibiotics and to deoxycholate}

Table 4 records the effect on sensitivity to six antibiotics and to sodium deoxycholate of several FOR alleles (the allele from FOR mutant SA486 was not tested, and those from mutants SL4442 and SL4443 were tested only for some of the agents). For each antibacterial agent, the minimum inhibitory concentration (m.i.c.) for each FOR mutant, FOR trans- 


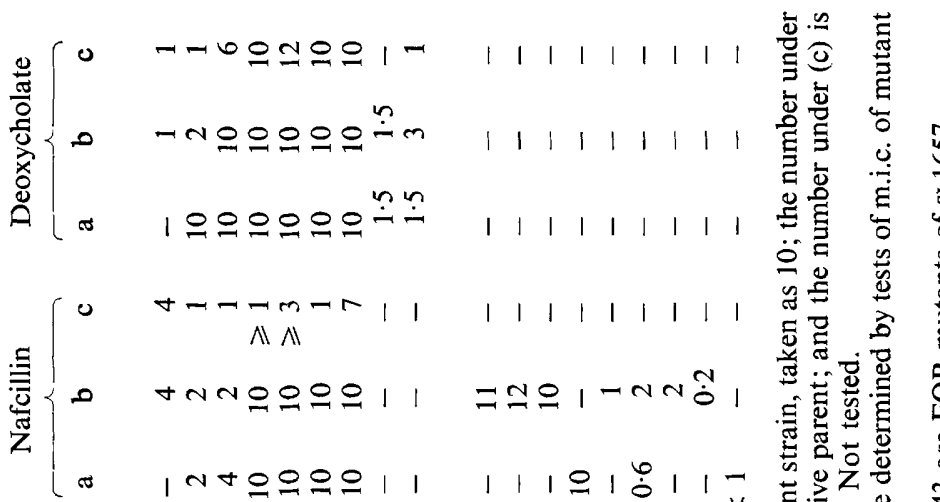

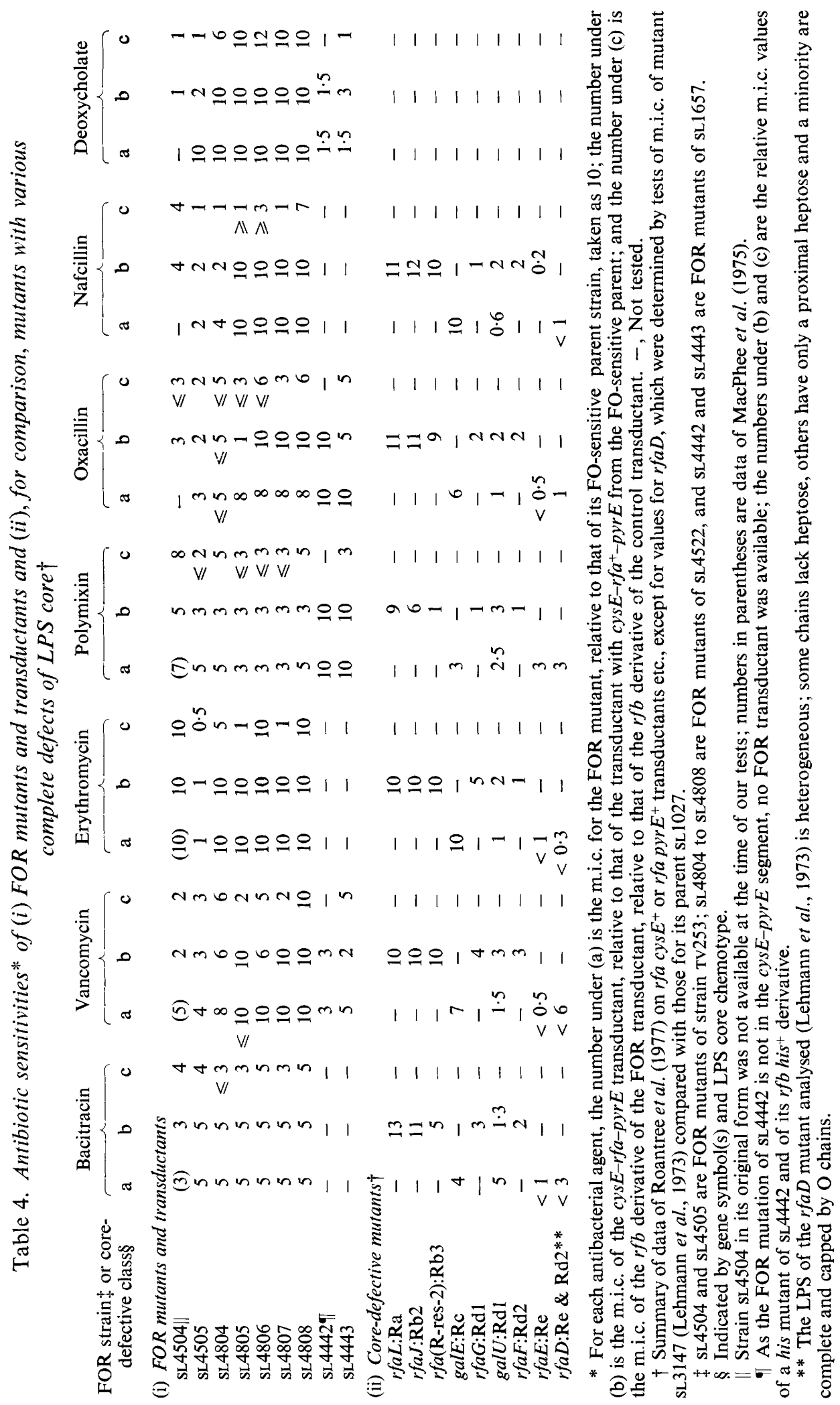


ductant and $r f b$ derivative of it was compared with the m.i.c. for the appropriate control strain, isogenic except for possession of wild-type gene instead of $r f a(F O R)$ mutant allele; in Table 4 the m.i.c. for each control strain is set at 10 . The similarly expressed sensitivities characteristic of strains with different core defects, resulting from $\mathrm{rfa}$ or galE or galU mutation, are included in Table 4 for comparison; the numbers shown are a summary of the data of Roantree et al. (1977) for all classes except $r f a D$ (Lehmann et al., 1973), which we found by comparison of m.i.c. values for the $r f a D$ mutant SL 3147 with those for its smooth parent SL1027. The data for mutants SL4442 and SL4443 must be interpreted with caution since the control parent strain, SL1657, has a galE mutation, not detectable in the FOR mutants, and galE mutation by itself causes some increases in antibiotic sensitivity. Each of the nine FOR alleles tested caused at least a twofold reduction in m.i.c. (in some instances, a 10-fold reduction) for at least two agents. For some of the FOR alleles and some antibacterial agents the sensitizing effect was apparent only in the $r f b$ derivative of the FOR transductant and not in the original mutant.

\section{DISCUSSION}

Our results, we consider, confirm the hypothesis that the FOR phenotype results from defective LPS core structure, but show that several different defects, and mutations in more than one gene, can produce the FOR phenotype. The 10 FOR mutants studied can be grouped according to inferred core defect, as in Table 5, which summarizes their properties. We shall consider each such group in turn.

Mutants inferred to have LPS with some type Rc core chains. Five FOR mutants, four in the M7471 line and one in an LT2 line (Table 5), differed from the other five FOR mutants in that transductants given their $r f a(\mathrm{FOR})$ alleles and $r f b$ derivatives of such transductants were both partly sensitive to phage $\mathrm{C} 21$ (e.o.p. $10^{-7}$ to $10^{-3}$ ) (Tables 2 and 5). The phage sensitivities of the transductants were otherwise as expected (FOR pattern), and those of their $r f b$ derivatives showed the R-sensitive pattern. However, the $r f b$ derivatives allowed an e.o.p. of only about 0.1 for FO phage and adsorbed it only 0.13 to 0.20 times as rapidly as the control, non-FOR, $r f b$ strains. The LPS from all five FOR $r f b$ derivatives had significant inhibitory activity in the Rc (galactose-deficient) LPS haemagglutination system but in no other tested (Table 3); the four FOR alleles investigated caused moderate increases in sensitivity to polymyxin and bacitracin, as does galE mutation (Roantree et al., 1977; Table 4). We infer that these five FOR alleles prevent the completion of some core chains and that the uncompleted chains terminate in glucose I lacking both galactose units, so that some core units are of type Rc, as found in the LPS of galE mutants, unable to make UDPgalactose. As these FOR mutants ferment galactose their failure to add galactose units cannot result from inability to synthesize UDPgalactose. Their inferred core defect does not correspond to that of any previously identified class of mutant resulting from alteration of a $r f a$ gene located in the $c y s E-p y r E$ segment: $r f a G$ mutants though sensitive to phage $\mathrm{C} 21$ are deficient in addition of glucose I and the $r f b$ FOR LPS were not serologically related to the Rdl (glucose-deficient) LPS of a $r f a G$ mutant (Table 3); $r f a($ R-res-2) mutants are not sensitive to C21 and their LPS core though lacking galactose I possesses the galactose II branch unit, and the FOR $r f b$ LPS did not cross-react serologically with the LPS of a mutant of this class (Table 3). Mutants of class $r f a H$ are sensitive to phage C21 (Wilkinson \& Stocker, 1968) but locus $r f a H$ is near metE (Kuo \& Stocker, 1972; Stocker \& Takano, unpublished observations), far from the cysE-pyrE segment. It thus seems likely that the five C21-sensitive FOR mutants arise by mutation of previously unidentified $r f a$ gene(s) located in the cysE-pyrE segment and concerned with addition of both the galactose units of the core. No non-leaky $r f a$ mutations causing production of LPS core, all of which is of type Rc, have been found in $S$. typhimurium, and several of the C21-sensitive FOR mutations are of type amber (Stocker \& Church, unpublished observations). This makes it unlikely 


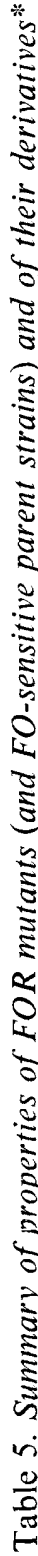

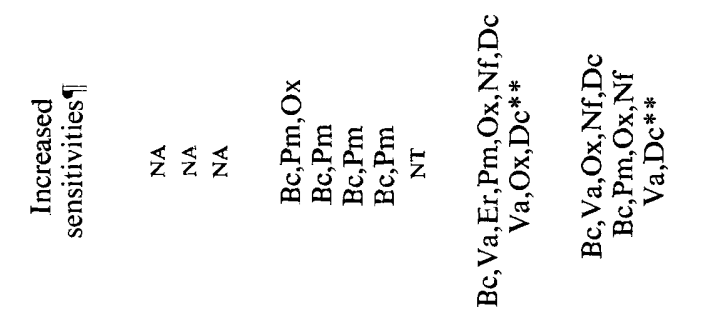

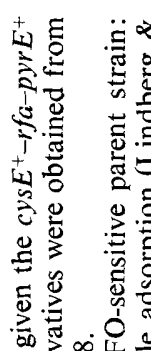

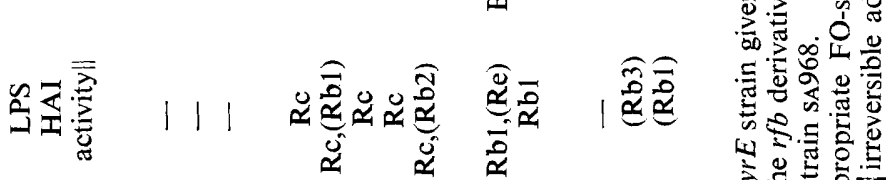

$\underline{2}$

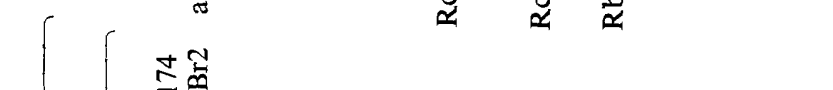

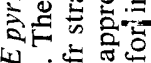

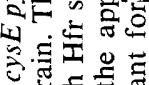

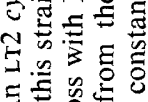

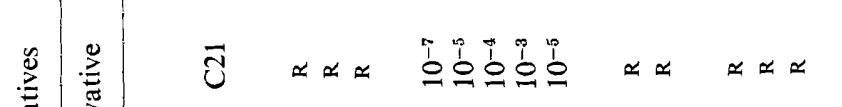

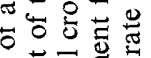

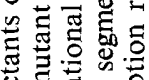

$\frac{0}{0}\left\{\begin{array}{l}0 \\ 0 \\ 0\end{array}\right.$

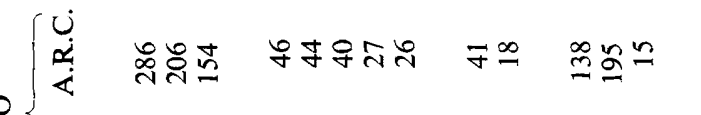

贾运

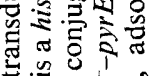

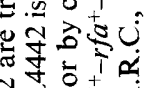

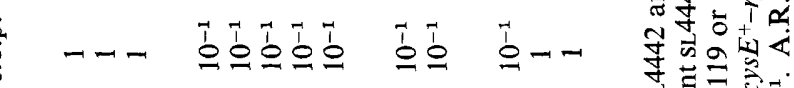

\section{蛋}

L

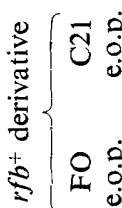

000

tis

00000

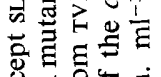

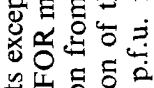

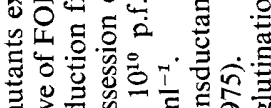

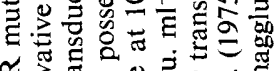

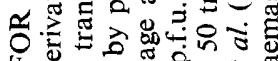

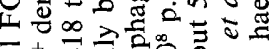

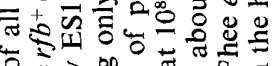

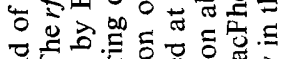

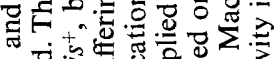

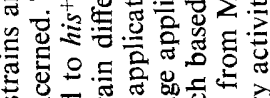

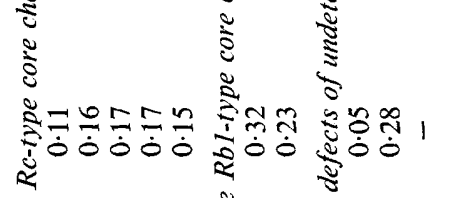

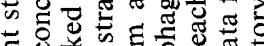

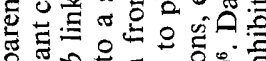

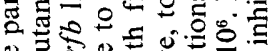

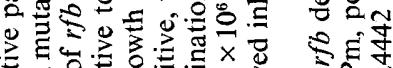

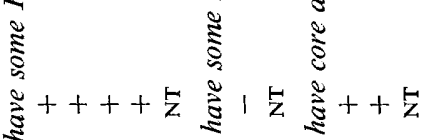

이의

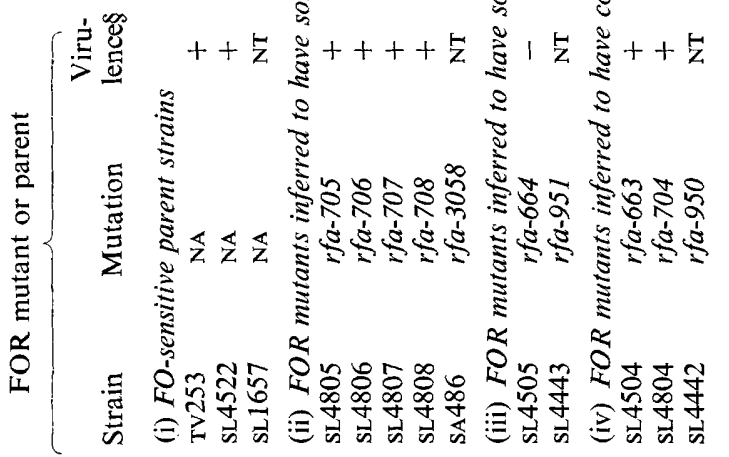

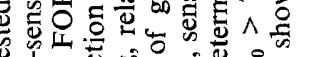

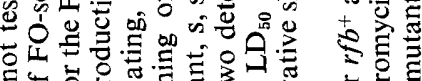

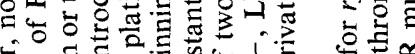

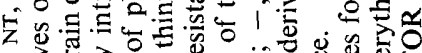

i. 跑

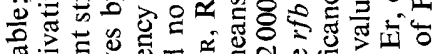

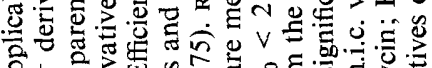

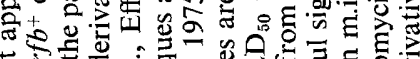

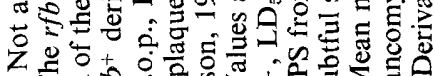

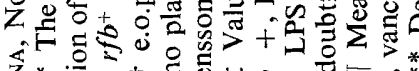

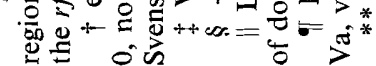


that the C21-sensitive FOR phenotype results from 'leaky' mutation of a gene specifying a polypeptide component common to the two transferases which are presumably needed for formation of the galactose I and II units. Another possibility is that the mutations affect a gene responsible for a modification of the inner core (e.g. addition of a branch unit) and that absence of the modification impedes but does not entirely prevent addition of the galactose I and II units. In $S$. minnesota, mutation $r f a P$ prevents attachment of a phosphate branch to the heptose part of the core (Mühlradt, 1971); this defect prevents the core chain from being extended beyond glucose I (not beyond glucose II, as by error previously stated, MacPhee et al., 1975). Mutation at $r f a P$ might produce the C21-sensitive FOR phenotype if the mutation was 'leaky' or if, in S. typhimurium, some phosphate-deficient core chains accepted at least the galactose I unit. Another possible function for the gene or genes affected in these FOR mutants is specification of a galactosyl transferase for formation of the galactose II branch unit, if absence of the branch prevents addition of the galactose I unit on some core chains, so that some end in glucose lacking both galactoses and others lack only the galactose II branch; if these latter chains could accept the distal units of the core, the FOR phenotype would be accounted for. The five $\mathrm{C} 21$-sensitive FOR mutations were cotransduced with $c y s E$ at frequencies between 0.11 and $0 \cdot 17$, consistent with mutation of a single gene. However, their pyrE cotransduction rates ranged from 0.13 to 0.46 , which suggests involvement of more than one gene.

$F O R$ mutants with inferred defects in addition of $\mathrm{N}$-acetylglucosamine unit and in deep part of core. Two FOR mutants, SL4443 and the nonvirulent SL4505, are grouped because the LPS of their $r f b$ derivatives were serologically related to LPS of type Rb1, i.e. lacking the $N$-acetylglucosamine branch unit (Fig. 1, Tables 3 and 5). The $r f b$ derivatives with the FOR alleles of these two mutants differed from control $r f b$ derivatives by much slower adsorption of $\mathrm{FO}$ phage and by resistance to phages $\phi \times 174$ and $\mathrm{Br} 2$, which are inactive on strains with deep core defects but plate efficiently on those with superficial defects, including $r f a K$ mutants, whose LPS core lacks the $N$-acetylglucosamine branch (Lindberg, 1973; Stocker \& Mäkelä, 1971). Both FOR alleles caused increased sensitivities to oxacillin and deoxycholate, characteristic of deep core defects (Tables 4 and 5). Thus two lines of evidence suggest the mutants have deep core defects whereas the serological results indicate a superficial defect in each mutant. If, as we think, both mutants arose by single mutations, one genetic defect apparently causes two core lesions. The cotransduction frequencies (Table 5) indicate that both mutations are closer to cysE than to pyrE, and are compatible with mutation at $r f a D$, concerned with an epimerization step in biosynthesis of the heptose precursor (Lehmann et al., 1973) or at $r f a F$, for formation of the heptose II unit (Kuo \& Stocker, 1972). The FOR mutation of SL4505 causes loss of virulence (MacPhee et al., 1975); the weak Re activity of the related LPS and its lack of activity in the Rd2 system (Tables 3 and 5) may point to $r f a D$ as the site of the FOR mutation of sL4505.

Mutants inferred to have unidentified LPS core defects. The last three FOR mutants form a group only in that serological testing of LPS from their $r f b$ derivatives gave no indication as to the nature of their inferred core defects. The FOR allele of strain SL 4504 did not cause complete FO-resistance in $r f b^{+}$strains and in the $r f b$ derivative allowed adsorption of FO phage at half the normal rate (Table 5); probably this mutation causes only a moderate reduction in the number of completed core chains. This FOR allele caused increases in sensitivity to antibacterial agents, suggestive of a defect in the deep part of the core. However, the map position indicated by cotransduction frequencies, i.e. much closer to pyrE than to $c y s E$ (Table 5), does not correspond to any known $r f a$ gene affecting deep LPS core structure, and SL4504 FOR $r f b$ LPS inhibited neither Re nor Rd2 haemagglutination. This FOR mutation may cause a deep core defect, such as absence of a heptose or phosphate branch, not detectable by the available defective-core haemagglutination-inhibition systems.

The FOR mutation of SL4804 caused the FOR phenotype in the original mutant but only 
a minor degree of FO resistance in the LT2 transductant and no decrease in the rate of $F O$ adsorption by the $r f b$ derivative; perhaps this allele causes only a slight reduction in the proportion of core chains completed, or a change in the core chain structure which only slightly reduces affinity for FO phage. The increases in sensitivity caused by this mutant gene, especially to oxacillin, suggest a defect in formation of the glucose I unit, or deeper, and its location, closer to $c y s E$ than to $p y r E$, corresponds approximately to those of $r f a F$ and $r f a D$, both affecting the heptose part of the core. However, the negative serological evidence prevents any conclusion as to the part of the LPS core affected by the SL4804 mutation.

The mutation of SL4442, a new FOR mutant in an LT2 line, was not between cysE and pyrE; Hfr crosses showed it to be in the 90 to 116 min segment. This mutation caused a 10 -fold reduction in the rate of adsorption of FO by a $r f b$ derivative, and sensitivity to deoxycholate, which suggests a deep core defect. The inferred site of the mutation is compatible with it being a 'leaky' allele of $r f a E$, a gene involved in formation of the heptose I unit (Wilkinson et al., 1972; Kuo \& Stocker, 1972). However, sL4442 rfb LPS did not inhibit the Re haemagglutination system.

Effect of FOR mutation on sensitivity to antibiotics and deoxycholate. If, as we postulate, FOR mutants have an LPS core defect, the increased sensitivity of such strains to certain antibiotics etc. presumably arises by the mechanism which causes increased sensitivity of some $r f a$ mutants to these substances (Roantree et al., 1977; Schlecht \& Schmidt, 1969). Nikaido (1976) proposed that the increased sensitivity of 'deep rough' mutants to hydrophobic antibiotics (such as nafcillin or erythromycin) results from absence or great reduction in the amount of major outer membrane proteins in the outer leaflet of their outer membranes; the absent proteins are replaced by phospholipids, resulting in an outer surface which is in part hydrophobic. If this explanation applies to FOR mutants, their outer membranes should contain subnormal amounts of the major outer membrane proteins, and have phospholipids exposed at the surface - predictions which remain to be tested. In the experiments of Roantree et al. (1977), lack of $r f a L$ function, for attachment of O sidechains to complete core LPS, caused no increase in sensitivity to the antibiotics tested by us, with the exception of polymyxin. In our experiments, the introduction of a $r f b$ mutation, preventing synthesis of $\mathrm{O}$ units, into some FOR transductants resulted in substantial increases in sensitivity to certain antibiotics (see FOR alleles of SL4805 and SL4807, vancomycin, erythromycin, in Table 4). It seems, then, that the presence or absence of $O$ chains on complete core LPS makes no difference to the permeability of the outer membrane, but that the presence of $O$ chains may greatly influence the permeability of outer membranes containing LPS with incomplete core defects of the FOR type or types. In some instances a FOR mutation which did not cause antibiotic sensitivities in the original mutant did cause sensitivity, including in some instances sensitivity to deoxycholate, when introduced by transduction into an LT2 host (Table 4). We do not know the explanation for this, but suspect that it reflects some difference, probably only quantitative, between the LPS structure of the original mutants, most of them in the mouse-virulent $\mathrm{M} 7471$ line, and that of the LT2 line, which is relatively non-virulent. (Some such difference in wild-type LPS structure, for instance in the mean length of $\mathrm{O}$ chains or in the distribution of $\mathrm{O}$ chain lengths, or in the proportion of complete core chains not capped by $\mathrm{O}$ chains, is presumably responsible for the lower e.o.p. of FO phage on smooth derivatives of $S$. typhimurium $\mathrm{M} 7471$, compared with the e.o.p. on LT2 derivatives.)

Unmasking of FO adsorption sites. If FOR mutants are resistant to FO phage only because the few complete core chains present in their LPS are masked by $\mathrm{O}$ chains then anything preventing such masking should make them FO-sensitive. Genetic defects, either $r f b$, preventing formation of $\mathrm{O}$ units, or $r f c$, preventing their polymerization, or $r f a L$, preventing attachment of $\mathrm{O}$ chains to core, have this effect (Table 2; MacPhee et al., 1975; Hudson, 1976). A further demonstration of the masking of the FO receptor by $O$ chains 
in FOR bacteria is the effect of treatment of such cells with P22 phage tails, or with the endoglycosidase associated with them, which breaks the rhamnoside bonds in alternate $\mathrm{O}$ units of the LPS of smooth $S$. typhimurium. Suspensions of FOR cells treated with enzyme, then exposed to FO phage, then to anti-FO serum produced higher counts of plaque-forming units than did control samples not exposed to P22 tail enzyme (A. A. Lindberg, unpublished observations). Another way of unmasking the FO receptor site is by use of converting phages to interfere with synthesis of $\mathrm{O}$ units. A strain of Salmonella anatum made lysogenic for $\epsilon 15$ and therefore of $O$ constitution 3,15 was resistant to FO phage (Wright \& Barzilai, 1971). The resistance of this strain, and of smooth strains of many other species of group E, presumably results from the absence or small number of complete core chains not bearing long $\mathrm{O}$ chains. Lysogenization of $\mathrm{O} 3,15$ bacteria by phage $\epsilon 34$ causes attachment of a glucose branch to the galactose of the 3,15 repeat unit, resulting in appearance of $\mathrm{O}$ factor 34; glucose is first transferred from UDPglucose to antigen carrier lipid, then from antigen carrier lipid to the O unit (Wright, 1971). Lysogeny for phage $\varepsilon 34$ under conditions preventing addition of glucose to the $\mathrm{O}$ unit (either $\mathrm{O}$ unit of inappropriate type or mutation of the phage gene for the second step of transfer) resulted in a reduction in amount of O-specific material in LPS and in appearance of sensitivity to FO phage (Wright \& Barzilai, 1971), effects attributed to blocking of antigen carrier lipid sites by glucose, causing a reduction in rate of O-unit synthesis. A somewhat similar effect has been seen in the case of FOR mutants of S. typhimurium. Phage P22 causes attachment of a glucose to C- 6 of the galactose of the $\mathrm{O}$ repeat unit, detectable by appearance of antigen $\mathrm{O} 1$; this antigen is expressed in all or nearly all cells in cultures newly made lysogenic for P22 (Stocker et al., 1960). A mutant phage, P22.al, does not cause production of factor 1 (Young et al., 1964) because of deficiency of the enzyme for transfer of glucose from antigen carrier lipid to the $\mathrm{O}$ unit (C. W. Shuster, personal communication; cf. Mäkelä, 1973). Several FOR mutants newly infected with P22.al supported production of plaques by FO phage (Hudson \& Stocker, unpublished observations); by contrast, established P22. al lysogenic derivatives of the FOR strains remained resistant to FO phage, probably because many bacteria in established P22-lysogenic cultures do not express factor 1 owing to 'form-variation' causing non-expression of at least the gene for the first of the two glucosetransferring enzymes.

This investigation was supported by United States Public Health Service Grant AI07168 awarded by the National Institute of Allergy and Infectious Diseases, a Fogarty International Fellowship No. F 5 TW1912 from the National Institutes of Health, and a Swedish Medical Council Grant No. 40X-656. This work is based on the Ph.D. dissertation (Stanford University, 1976) of Helen P. Hudson.

\section{REFERENCES}

Boro, H. \& Brenchley, J. E. (1971). A new generalized transducing phage for Salmonella typhimurium LT2. Virology 45, 835-836.

Galanos, C., Lüderitz, O. \& Westrhal, O. (1969). A new method for the extraction of $\mathrm{R}$ lipopolysaccharides. European Journal of Biochemistry 9 , 245-249.

Gemski, P. \& Stocker, B. A. D. (1967). Transduction by bacteriophage P22 in nonsmooth mutants of Salmonella typhimurium. Journal of Bacteriology 93, 1588-1597.

Hudson, H. P. (1976). Ph.D. thesis, Stanford University, U.S.A.

Krishnapillai, V., MacPhee, D. G. \& Stocker, B. A. D. (1971). Properties of a Salmonella typhimurium mutant with an incomplete deficiency of uridine-diphosphogalactose-4-epimerase. Journal of Bacteriology 107, 155-161.

Kuo, T.-T. \& STOCKer, B. A. D. (1970). ES18, a general transducing phage for smooth and nonsmooth Salmonella typhimurium. Virology 42, 621-632.

Kuo, T.-T. \& STocker, B. A. D. (1972). Mapping of $r f a$ genes in Salmonella typhimurium by ES18 and P22 transduction and by conjugation. Journal of Bacteriology 112, 48-63.

LehmanN, V., Hämmerling, G., Nurminen, M., Minner, I., Ruschmann, E., Lüderitz, O., Kuo, T.-T. \& Stocker, B. A. D. (1973). A new class of heptose-defective mutant of Salmonella typhimurium. European Journal of Biochemistry 32, $268-275$. 
LeviNe, M. (1972). Replication and lysogeny with phage P22 in Salmonella typhimurium. Current Topics in Microbiology and Immunology 58, 135-156.

LINDBERG, A. A. (1973). Bacteriophage receptors. Annual Review of Microbiology 27, 205-241.

LindberG, A. A. \& Hellerqvist, C. G. (1971). Bacteriophage attachment sites, serological specificity, and chemical composition of the lipopolysaccharides of semirough and rough mutants of Salmonella typhimurium. Journal of Bacteriology 105, 57-64.

LindBerG, A. A. \& Holme, T. (1972). Evaluation of some extraction methods for the preparation of bacterial lipopolysaccharides for structural analysis. Acta pathologica et microbiologica scandinavica 80B, 751-759.

Lindberg, A. A. \& Svensson, S. (1975). Salmonella typhimurium mutations conferring resistance to Felix $O$ phage without loss of smooth character: phage attachment and immunochemical and structural analyses of lipopolysaccharides. Journal of General Microbiology 87, 11-19.

MacPhee, D. G. \& Stocker, B. A. D. (1969). Suppression of amber and ochre mutants in Salmonella typhimurium by a mutant $F^{\prime}-1-g a l$ factor carrying an ochre suppressor gene. Journal of Bacteriology 100, 240-246.

MacPhee, D. G., Krishnapillai, V., Roantree, R. J. \& Stocker, B. A. D. (1975). Mutations in Salmonella typhimurium conferring resistance to Felix $\mathrm{O}$ phage without loss of smooth character. Journal of General Microbiology 87, 1-10.

Mäkel ̈̈, P. H. (1973). Glucosylation of lipopolysaccharide in Salmonella: mutants negative for $\mathrm{O}$ antigen factor $12_{2}$. Journal of Bacteriology 116, $847-856$.

Morgenroth, A. \& Duguid, J. P. (1968). Demonstration of different mutational sites controlling rhamnose fermentation in FIRN and non-FIRN rha- strains of Salmonella typhimurium. Genetical Research 11, 151-169.

MüHLRadT, P. F. (1971). Biosynthesis of Salmonella lipopolysaccharide. Studies on the transfer of glucose, galactose and phosphate to the core in a cell-free system. European Journal of Biochemistry 18, 20-27.

Nikaido, H. (1976). Outer membrane of Salmonella. Transmembrane diffusion of some hydrophobic molecules. Biochimica et biophysica acta 433, $118-132$

Ornellas, E. P. \& Stocker, B. A. D. (1974). Relation of lipopolysaccharide character to P1 sensitivity in Salmonella typhimurium. Virology $\mathbf{6 0}$, 491-502.

Roantree, R. J., Kuo, T.-T. \& MacPhee, D. G. (1977). The effect of defined lipopolysaccharide core defects upon antibiotic resistances of Salmonella typhimurium. Journal of General Microbiology 103, 223-234.

Sanderson, K. E. \& SaEed, H. (1972). Insertion of the $\mathrm{F}$ factor into the cluster of $r f a$ (rough $\mathrm{A}$ ) genes of Salmonella typhimurium. Journal of Bacteriology 112, 64-73.

SAnderson, K. E., Ross, H., Ziegler, L. \& Mäkelä, P. H. (1972). $\mathrm{F}^{+}, \mathrm{Hfr}$ and $\mathrm{F}^{\prime}$ strains of Salmonella typhimurium and Salmonella abony. Bacteriological Reviews 36, 608-637.

Schlecht, S. \& Schmidt, G. (1969). Möglichkeiten zur Differenzierung von Salmonella-R-Formen mittels Antibiotica und antibakterieller Farbstoffe. Zentralblatt für Bakteriologie, Parasitenkunde, Infektionskrankheiten und Hygiene (Abteilung I, Orig.) 212, 505-511.

Schmidt, G., Schlecht, S., LÜderitz, O. \& WestPHAL, O. (1969). Untersuchungen zur Typisierung von Salmonella-R-Formen. 1 Mitteilung: Mikrobiologische und serologische Untersuchungen von Salmonella minnesota Mutanten. Zentralblatt für Bakteriologie, Parasitenkunde, Infektionskrankheiten und Hygiene (Abteilung I, Orig.) 209, 483-496.

SCHMIEGER, H. (1972). Phage P22-mutants with increased or decreased transduction abilities. Molecular and General Genetics 119, 75-88.

Smith, H. \& Levine, M. (1967). A phage P22 gene controlling integration of prophage. Virology 31, 207-216.

Stocker, B. A. D. \& MÄKel.̈, P. H. (1971). Genetic aspects of biosynthesis and structure of Salmonella lipopolysaccharide. In Microbial Toxins, vol. 4, pp. 369-438. Edited by G. Weinbaum, S. Kadis \& S. J. Ajl. London: Academic Press.

Stocker, B. A. D., Staub, A. M., Tinelli, R. \& KopackA, B. (1960). VI. Étude de l'antigène 1 present sur deux Salmonella des groupes $B$ et $\mathrm{E}_{4}$. Annales de l'Institut Pasteur 98, 505-523.

Subbaiah, T. V. \& Stocker, B. A. D. (1964). Rough mutants of Salmonella typhimurium. 1. Genetics. Nature, London 201, 1298-1299.

Walsh, J. \& Meynell, G. G. (1967). The isolation of non-excluding mutants of phage P22. Journal of General Virology 1, 581-582.

Wilkinson, R. G. \& Stocker, B. A. D. (1968). Genetics and cultural properties of mutants of Salmonella typhimurium lacking glucosyl and galactosyl lipopolysaccharide transferases. Nature, London 217, 955-957.

Wilkinson, R. G., Gemski, P. \& Stocker, B. A. D. (1972). Nonsmooth mutants of Salmonella typhimurium: differentiation by phage sensitivity and genetic mapping. Journal of General Microbiology 70, 527-544.

WRIGHT, A. (1971). Mechanism of conversion of the Salmonella $\mathrm{O}$ antigen by bacteriophage $\epsilon^{\mathbf{3 4}}$. Journal of Bacteriology 105, 927-936.

Wright, A. \& BARZILAI, N. (1971). Isolation and characterization of nonconverting mutants of bacteriophage $\epsilon^{34}$. Journal of Bacteriology 105, 937-939.

Young, B. G., Fukazawa, Y. \& Hartman, P. E. (1964). A P22 bacteriophage mutant defective in antigen conversion. Virology 23, 279-283. 